\title{
Repairing political trust in Tunisia
}

Sghaier, M., Skandrani, H. and Robson, J (2021) Repairing political trust in Tunisia. Qualitative Market Research: An International Journal. (in press)

\begin{abstract}
Purpose: this study aims to identify the responses required to repair political trust in Tunisia and the differences between two key stakeholder groups, namely politicians and voters.

Design/methodology/approach: A qualitative longitudinal study was adopted using two data sources: media data from TV political talk shows; and semi-structured interviews conducted with citizens and politicians. Data was collected following several key events that violated trust.

Findings: New responses were identified to repair political trust and these were categorized using a trust repair framework. In addition to short and long-term responses a new category, swift response, was identified to resolve immediate political uncertainty. The role of the trustor (i.e. voters) in actively restoring trust was identified for the first time.
\end{abstract}

Research limitations: This study focused on trust repair responses suggested by voters and politicians and not responses that were implemented by the government or political parties during the period of study. The effectiveness of the suggested responses in repairing trust was not therefore evaluated.

Practical implications: Identification of the responses required to repair trust with voters and how these differ over time and according to different trust violations will help Tunisian politicians rebuild trust more effectively during election and non-election periods. Notably, differences highlighted between the responses suggested by voters and politicians suggest that politicians may not understand how to repair voter trust.

Originality/value: Contrary to previous studies that assume a trustor (the voter) is a passive observer, this research identified the proactive role that citizens play in the trust repair process.

Keywords: trust repair, political marketing, media data, interviews, Tunisia, longitudinal study. 


\section{INTRODUCTION}

In the recent past, surveys have repeatedly reported society's trust in government and political systems at an all-time low. The most recent, the Edelman Trust Barometer (Edelman, 2020), positions government at the lowest level of trust for all institutions in terms of ethics and competence. Political trust is however critical in influencing electoral attitude and voters' behaviour (Hetherington, 1999). Voters have changed over the years, becoming more cynical (Ahmed et al., 2011), more volatile and more skeptical about politicians who rarely keep their promises (Klabi, 2012). Several authors have examined the antecedent of trust in an attempt to understand the relatively low levels of political trust among citizens (Chanley, 2002; Torcal, 2014.). Nevertheless, despite the large number of studies explaining what causes low levels of political trust, few have investigated how that lost trust can be repaired (Peng et al., 2016). Those that have examined trust repair have tended to focus on the image repair of political leaders after a crisis (Benoit and Henson, 2009; Garcia, 2011) and have largely been conducted in developed countries. The question that then arises is what responses can repair voter trust in an emerging country such as Tunisia. In answering this question, this study responds to several calls. First, Bozic (2017) highlighted the need to identify trust repair responses beyond apology and denial (which are also prominent in political trust repair studies) and to consider the needs of different stakeholders. Indeed, Bachmann et al. (2015) also observed that no single mechanism can be relied on to rebuild trust and suggested six potential trust repair mechanisms. We address these calls by uncovering an array of trust repair responses from two key stakeholder groups: voters and politicians. Second, Bachman et al. (2015) called for further research to investigate the extent to which trust repair is context bound. We address this by locating our study in an emerging but democratic country Tunisia. Bachmann et al. (2015) also called for longitudinal studies that examine how the need for trust repair changes over time. Our study covers a three-year period (2013 to 2015) and explores how the suggested trust repair strategies change after several political events that had a major impact on Tunisia. 


\section{THEORETICAL BACKGROUND}

The ease with which trust can be destroyed compared to the difficulty in repairing it is well recognized (Kim et al., 2004). Given that trust can be destroyed so quickly, it is important to identify the strategies or responses ${ }^{1}$ to restore trust when a violation occurs. In this section we will define the concepts central to this study, i.e., trust, trust erosion and trust repair. We then move on to identify the different responses available to organizations to repair trust and identify the trust repair framework used to underpin this study.

\section{Trust and trust erosion}

Trust is an abstract and complex concept (Bozic, 2017; Rousseau et al., 1998) and as a consequence, various definitions exist. Rousseau et al. (1998) defined trust as a psychological state, a willingness to be vulnerable due to the positive expectations we have of another. Mayer et al.(1995) echoed this inclination to be vulnerable regardless of the ability to monitor or control the other party and Schurr \& Ozanne (1985) defined trust as a belief in the words or promises of another party. Central to these definitions is an individual (the trustor) that is willing to place themselves in a position of vulnerability due to a belief in another party (the trustee). Dependency is implied due to an inability of the trustor to verify the words or promises of the trustee (Rousseau et al., 1998).

According to Lewicki and Wiethoff (2000), trust is eroded when the trustee fails to meet the trustor's expectations. As a result, there is a reduction in the perception of the trustee and the trustor may no longer be willing to be vulnerable (Dietz and Gillespie, 2012). A trust violation can be the result of a specific event or on-going, repeated transgressions. The violations can be intentional or unintentional and may be due to incompetence or a failure in integrity. The nature of the transgression will affect the extent of trust erosion.

\footnotetext{
${ }^{1}$ These two terms are used interchangeably in the literature, for clarity, we will use the term "responses" in this paper.
} 


\section{Trust repair}

Nakyachi and Watabe (2005) defined trust repair as the process of repairing and enhancing the perception of a trustee's trustworthiness. According to Dirks et al. (2011:4), repairing trust “involves attempting to increase trust following a situation in which a transgression (i.e., untrustworthy behaviour) is perceived to have occurred." Consequently, in contrast to building trust 'from scratch', repairing trust has to overcome negative expectations from the transgression. Trust and trust repair are therefore conceptually different.

Consumer trust within the political domain has repeatedly been identified as low (Edleman, 2020), consequently there have been calls for studies to investigate trust repair in this context (Kim and Kim, 2007). Extant studies have investigated the reasons behind the loss of trust towards the government, but studies examining trust repair are relatively few and the majority have focused on specific trust repair responses (Boursin, 1999; West, 2004; Kim and Kim, 2007; Moon, 2013). These responses can be classified as either verbal, which encompass denial and apology (see for example, Merrington et al., 2011; Grover et al., 2014; Liao, 2010) or substantive, which include e-government (e.g. online information), transparency and reforms (Tolbert and Mossberger, 2006; Kim and Kim, 2007; Grimmelikhuijsen et al. 2013; and Brillantes and Fernandez, 2011). In contrast to reviews conducted in other research areas and disciplines, this list is comparatively narrow. For example, in his review of the marketing and management literature Bozic (2017) identified 5 strategies: verbal responses (which includes denial, apology and information sharing); organizational restructuring (including reforms); penance; hostage posting and use of $3^{\text {rd }}$ parties. Bachamann's earlier study within organizational studies goes further to identify 6 broad mechanisms which encompass both the aforementioned studies (Bachamann et al., 2015). In summary, research within the political trust domain has to-date identified a limited range of trust repair responses. Bachman et al (2015) provide a comprehensive framework, and although the transferability of this framework to a non-organizational studies context has been 
questioned (Bozic, 2017) recent empirical research has demonstrated it applicability (see Bolat et al., 2020).

\section{Trust repair framework}

Bachmann et al. (2015) provide the most comprehensive framework for trust repair integrating six mechanisms or responses. Sense-making draws on the work of Weick (1995) and seeks to identify a shared understanding where the violation is expressed in words. The result is an accepted account of what happened, who caused the violation and what needs to be done going forward (Gillespie \& Dietz, 2009; Pfarrer et al., 2008). Public enquiries are an example of sense-making. The relational approach looks to re-establish social order by resolving negative emotions. Symbolic acts such as apologies, penance and resetting of expectations fall within this mechanism (Dirks et al., 2009; Stevens et al., 2015). Regulation and formal control aim to constrain untrustworthy behaviour via the imposition of external or internal interventions that clarify what behaviour is acceptable and what is not (Bachmann et al., 2015). Laws, policies and codes of contract are examples of regulation and formal control. Ethical culture and informal controls seek to promote ethical values and behaviour, for example, via staff induction, professional training or role models (McKendall \& Wagner, 1997; Martin, 2011). Transparency and accountability concerns the disclosure of relevant information enabling stakeholders to monitor the activities of an organization and assess their trustworthiness (Bachmann et al., 2015). Examples include corporate reporting and whistleblower protection. Finally, trust transference concerns the transfer of trust from a credible and trusted party to the distrusted party, for example via endorsement or affiliation (Bachmann \& Inkpen, 2011; Zucker, 1986).

The Bachmann et al. (2020) framework is based on the proposition that no single trust repair response can repair trust. They also caution that such responses are likely to vary by context and over time and called for future research to be conducted in different cultures and establish how use of the responses 
vary over time. Bozic (2017) also called for future research to consider the perspective of different stakeholders. Our longitudinal study responds to these calls as it seeks to understand which responses can repair trust among potential voters in an emerging country, Tunisia, by examining the viewpoints of politicians and citizens over time.

\section{RESEARCH METHOD AND STUDY CONTEXT}

A multi-method approach was adopted for this study comprising two discrete data sources: semistructured interviews with Tunisian politicians and citizens; and media data from TV political talk shows. Data collection centered on six key political events: (1) murder of the political opponent Chokri Belaid and (2) murder of the political opponent Mohamed Brahmi, both in 2013; (3) start of the National Dialogue and (4) adoption of the constitution both in 2014; (5) Parliamentary elections and (6) Presidential elections in 2015. Together these represent two negative and four positives events in which to examine trust repair responses.

Semi-structured interviews. 100 semi-structured interviews were conducted to provide rich and deep insight into political trust repair. Interviews were conducted at three time-points: first interviews with 38 citizens and 62 politicians were conducted after events (1) and (2); second with 11 citizens and 31 politicians after events (3) and (4); and third with 20 citizens and 10 politicians after events (5) and (6). In each round of interviews, interviewees were asked about both events. Informants were Tunisian citizens, as well as politicians belonging to ruling parties and opposition. Full details of the interviewees can be found in Appendix A and B. The final sample size was informed by theoretical saturation as recommended by Glaser and Strauss (1967). Interviews were conducted face-to-face and at a time and place convenient to the participants. They lasted approximately 40 minutes on average. All tapes were transcribed. 
Media data has the ability to explain current and past events (Tweedale, 2003) as it provides a wide range of readily accessible information that can deliver insider insights on a social subject (Franzosi, 1998). We selected political TV talk shows according to two criteria. First, we identified political shows with the highest audience rating in Tunisia namely, Ettounsya, Watanya 1 and Nessma (based on Sigma Conseil data); and second, we identified those shows that addressed the issue of political trust repair. All episodes from three political shows that ran in the month following each of the six events were included in this study. In total this represented 407 hours of aired programs. Each episode was reviewed and all sections that dealt explicitly or implicitly with the issue of trust repair responses were transcribed.

A database was constructed containing all transcripts from the study, i.e. from the interviews and TV shows (Yin, 2018). A thematic content analysis was conducted to identify political trust repair responses. As recommended by Lincoln and Guba (1985), the thematic analysis was created by one author and then peer reviewed. Transcripts were coded and comparisons made between responses given by the interviewed politicians and citizens and against the contributions of those appearing in the TV political talk shows. In addition, due to the longitudinal nature of this study, emerging themes were compared across the three events to identify similarities and differences emerging in the responses. Key themes emerged following a continuous and repeated comparison of the data (Patton, 2002), An unforeseen finding was the emergence of the citizen's role in the trust repair process from the interviews with politicians, further analysis was undertaken to identify if this also featured in the interviews with citizens.

Tunisia was selected as the context for this study as it was the first MENA country to experience the Arab Spring movement and change its political environment (Teti et al., 2018). Contrary to the Arab countries in which the revolutions took place (Libya, Syria and Egypt); Tunisia qualified as a 
democracy in 2017 following the successful 2014 elections (Teti et al., 2018). However, print media, broadcast news and polls have shown a continued low level of trust in all the political parties even after the parliament and presidential elections of 2014. Indeed, participation in the 2018 local elections was only $33.7 \%$, against $68.36 \%$ during the 2014 elections.

\section{FINDINGS}

Data analysis was two-part, first we identified if, and when, there was a need to repair trust; and second what responses were suggested to repair trust. Responses were categorized by time, guided by the typology of Lewicki and Brinsfield (2017), and according to the 6 Bachmann et al. (2015) trust repair mechanisms. We will begin by examining the perceived need to repair trust.

\section{The need to repair trust}

Political stakeholders and citizens agreed that there was a need to repair trust in the government and political parties, however, the strength of this need changed over time. In the interviews, trust repair was most frequently mentioned after the election in 2015. This was surprising given that trust was severely violated in 2013 with the murder of the two Tunisian opponents (Chokri Belaid and Mohamed Brahmi) and also several terrorist attacks causing the death of the Tunisian security forces. Following these dramatic events, both citizens and politicians agreed that it would be difficult, but not impossible, for political parties (whether ruling or not) to repair trust. Additionally, after the adoption of the constitution and the parliament and presidential elections of 2014, two theoretically optimistic events, talk shows participants (especially government representatives), stressed the need to repair trust towards political parties and government. This signals an awareness of an on-going political distrust. Notably, even the President of the Tunisian Republic expressed concern about political distrust and expressed the need for the government and the presidency institutions to act in a way that would restore trust in a speech in 2015: 
"we need to win trust. We need to trust in our capabilities and in the future of our country" (President of the Tunisian Republic).

\section{Swift trust repair}

When discussing trust repair, TV political talk show contributors identified the need for swift trust repair. This call was particularly observed after the assassination of political opponents. Under these circumstances, politicians were deemed not to have the luxury of time to repair trust due to a 'trust crisis'. Trust needed to be repaired quickly to resolve political uncertainty and to reach agreement on the adoption of the constitution and the holding of national elections. In order to do this, there was a need for dialogue, for parties to communicate with each other to make sense of what had happened and what needed to be done. This call for swift trust led to the National Dialogue that provided a way out of the political impasse between the government of Ennahdha and the opposition.

Swift trust has been identified previously and is defined as a form of trust occurring in temporary organizations in which "actors deal with one another more as roles than as individuals. Expectations, consequently, are more standardized and stable and defined more in terms of tasks than as personalities" (Grabher, 2002:210). Accordingly, the objective of swift trust, which is based mainly on roles, is to reach high levels of trust without having a prior relationship or experience (Meyerson et al., 1996).

\section{Short-Term Responses}

Three categories of short-term responses were identified relating to 1- political parties; 2- political institutions; and 3- citizens. 
Political parties. The majority of interviewees (citizens and politicians) identified 'having a realistic political program' as an important way in which to repair trust as the absence of concrete political programs was perceived as symptomatic of political parties' incompetence. This trust repair response was shaped by past experience and the failure of Ennahdha political program's 365 points presented before the 2011 elections and highlights a need for political parties to be accountable, setting and delivering on realistic targets.

Other short-term responses were identified across all data collection periods (i.e., 2013, 2014 and 2015) and align with a need for informal control to constrain untrustworthy behaviour. Specifically, all interviewees called for the different parties to cease quarreling and identify areas of agreement. Interviewees called on the political parties to recognize that citizens had voted for parties on all sides of the political spectrum and they needed to work together (even at the cost of sacrificing party views) to find solutions to the current political and economic crisis in the country. This suggestion reflects the Tunisian culture whereby ethnic and religious minorities and social groups work together to create a communication point and practice the art of negotiation (Rouissi, 1987). Additionally, Ouannes (2010) noted that Tunisians rapidly integrate and adapt and make concessions only if it helps them to achieve professional, material and social gains.

Apologies were suggested by a high number of interviewed politicians especially following the political murders in 2013 and the adoption of the constitution in 2014. Politicians called for the government and political parties to acknowledge their failure and take responsibility in order to successfully repair trust. In contrast, very few interviewed citizens mentioned an apology, highlighting a disparity between politicians and citizens, the latter under-estimating the level of political distrust among citizens towards the government and political parties. Quite simply, an apology, which is a symbolic act (Bachmann et al., 2015) was insufficient to restore trust with citizens when the magnitude 
of the trust violation was so large and resulted in high emotional reactions. Indeed, Farrell and Rabin (1996) have criticized apologies, describing them as a form of "cheap talk". Interviewed politicians also called for explanations to help to repair trust. Political party leaders had blamed their failure on others, a poor form of trust transference (Bachmann et al.,2015) instead of acknowledging their mistakes. Interviewees were however seeking an understanding of the trust violation, a shared understanding, or as Bachmann et al., (2015) would label this - sensemaking. Prior studies have found that explanations after a violation play a crucial role in repairing trust (Shapiro, 1991) and the more detailed they are, the more effective (Shapiro et al., 1994). Culture can influence the effectiveness of explanations which are more effective in collectivist cultures than individualistic ones (Ren and Gray, 2009; Maddux et al., 2011) which would reinforce their importance in Tunisia.

Political institutions. Short-term trust repair responses related to political institutions were the most frequently mentioned. In the period between the murder of Chokri Belaid and the adoption of the constitution in 2014, interviewed politicians agreed that holding elections and adopting the constitution were the way out from the Tunisian political trust crisis. Interviewees called for political leaders to end the transition period by holding parliamentary and presidential elections that would put in place a government with a longer-term mandate to guarantee political stability and better political and economic visibility. Findings from the media data supported this viewpoint. Indeed, after the murders of Chokri Belaid and especially Mohamed Brahmi, the recurrence of these two repair trust responses, especially among politicians which aim to put in place formal control, was witnessed.

Other respondents, especially from the TV show participants, suggested more radical but peaceful responses, namely the creation of a technocratic government and the resignation of the government dominated by Ennahdha and the dissolution of the National Assembly, to repair political trust among citizens. Using Bachmann et al.'s (2015) framework, all fall within the relational approach as the 
suggestions result in a redistribution of power and resetting of expectations; these symbolic acts serve to resolve negative emotions caused by the violations (in this case the two political murders in 2013).

Two further means with which to repair trust in political institutions were mentioned by a minority of interviewees. First citizens called for the benefits and the salaries of ministers to be reduced:

"at this time of crisis, it is not normal to see so many ministers, not to mention their salaries. It is therefore mandatory to revise the benefits and salaries of the current ministers." (Female, 2013, interview)

This can be viewed as a form of penance in order to re-establish social order (Bachmann et al, 2015). Indeed, after his appointment in 2016, the head of government reduced minsters' remuneration by 10\%. Results of a Sigma Conseil poll two months later confirmed the effectiveness of this response as the performance of the government, for its first 100 days, was estimated as positive by $45.8 \%$ of Tunisians. The second trust repair response to be mentioned by a few study participants, in this case interviewed politicians, identified the need for the involvement of an external third party. The suggestion was that a third party can resolve conflict and mediate the process of trust repair. Third parties are viewed as a form of trust transference by Bachmann et al (2015). Prior studies have highlighted the importance of third party mediation in the trust repair process (Tomlinson and Mryer, 2009; Yu et al., 2015), however its influence of on trust repair is still under-studied (Klein Woolthuis et al., 2014).

Citizens. The role of citizens in the trust repair process was identified as a short-term response. This is a novel suggestion as the focus is on trustor actions, i.e. the person who trusts another person or entity, rather than the trustee as the person or entity being trusted. Civic engagement by citizens (the trustors) was identified by the interviewed citizens and politicians and TV political talk shows participants. 
Respondents called for citizens to bury their differences and unite to smooth the trust repair process and hold politicians accountable:

"The President of the Republic had previously all the powers and consequently we were not able to question him. It is important to admit today that thanks to the struggles of the democratic forces, the accountability of the President of the Republic is henceforth recognized in the 2014 constitution. People have the power now to sanction also political parties during elections." (Female, 2014, media data).

This statement demonstrates the empowerment of citizens to exercise their civic duty and hold politicians accountable.

\section{Long-Term Responses}

Long-term trust repair responses have received less attention in the literature (Lewicki and Brinsfield 2017), however this study identified a range of responses suggested for longer term trust repair.

Political parties and government. Almost all interviewed politicians across the three events highlighted the failure of political parties and government to communicate with citizens. They suggested that communication can improve politicians' image and restore trust. A high number of interviewed citizens and a few TV political talk contributors echoed this view. All noted that politicians should know how to manage a crisis that requires good communication skills. Transparent communication was required to reassures voters in a situation of increased political uncertainty and anxiety: 
"The opposition parties must keep a clear and unambiguous speech that draws a clear guideline. Their speeches must be immutable.” (Male, 2013, interview).

Moreover, citizens called for direct forms of communication between the political parties and citizens, favoring direct personal contact:

Communication through periodic meetings and door-to-door canvassing will allow closer relationships with citizens. I believe that personal contacts are effective means to repair trust (Male, 2015, interview).

This direct contact is characteristic of the Tunisian culture, where people like to maintain social contact and derive pleasure in multiple social interactions (Skandrani et al., 2011). However, according to Boursin (1999:9), communication is not always the best strategy to restore trust after a violation, as this requires deep reaching and tangible change.

There was a common agreement across all data sources that in order to repair political trust in political parties and government the political parties needed to fulfil their electoral promises, especially after the parliament and presidential elections:

When we announce projects, we have to be able to realize it. This is one aspect of the trust between the government and officials and the people. This allows restoring trust between government and citizens. (Male, 2013, media data).

Extant studies have generally assumed that there is a correlation between fulfilling electoral promises and electorates' behavior. For instance, Pétry (2014) suggests that keeping campaign promises is a fundamental component of democratic responsiveness. Nevertheless, empirical studies regarding this 
relationship are lacking. This response has been classified as ethical culture and informal control (Bachmann et al., 2015 framework) as there are no formal rules or controls to ensure parties deliver on their promises, it is an ethical choice to deliver on the promises made.

Government. six trust repair responses were identified from the data analysis related to government, namely: economic responses, regulation, fight against corruption, ensuring security, respect for freedom and fairness.

Economic response - this trust repair response stems from the Tunisia's fragile economic situation and economic crisis. Interviewed politicians and citizens and TV talk shows contributors cited several issues underpinning the call for improvement in the economy in order to restore trust: the significant drop in Tunisian people's purchasing power since the revolution; an increase in unemployment rate; rising regional and social inequalities; and disparities between the coastal areas and those in land. The need to improve the economy was therefore viewed as a priority. Prior studies identified the influence of the economic situation on levels of political trust. Indeed, past studies have found that economic performance in itself can explain a fall in political trust (Hetherington, 1998), however no previous studies have identified the relationship between economic reform and trust repair. Prima facie this response is difficult to classify within the Bachman et al. (2015) framework. Discussions within the group and repeated cross-referencing between the data and framework resulted in this response being classified as trust transference. Although the economy is not a third party as such, a positive turn in the economy would be used as an example of the trust repair undertaken by the political party: a form of reputation spillover (Bachman et al., 2015).

The majority of interviewed politicians and citizens suggested that regulation of party funding could repair citizens' distrust of political parties and government, particularly after the political murders and 
2014 elections; and to a lesser extent after the adoption of the constitution. Contributors to the TV political talk shows, especially politicians, cited a lack of public control over political parties' funding and the need for public authorities to implement a strict law regulating how political parties operate (regulation and formal control). Regulations are required to prevent donations from illegal sources as the sources of almost all the existing legal political parties remain largely unknown. Moreover, the victory of Ennahdha in the 2011 elections is closely connected to its suspicious financial funds. Previous studies have also argued that regulation could be effective in repairing trust (Dirks et al., 2011; Gillespie and Dietz, 2009; Eberl et al., 2015). Indeed, they consider that the presence of strict laws in response to an integrity-based violation sends a clear signal that the behavior is unacceptable and thus will be avoided in the future.

Fighting against corruption was reported by interviewed citizens and politicians, especially after the political murders and the 2014 elections. According to respondents, the government had been weakened by political instability enabling the spread of corruption and clientelism was threatening the democratic transition in Tunisia. Previous studies have identified that fighting corruption is perceived as an important measure of political performance (Lambsdorff, 2007) and that citizens support institutions that are reducing corruption (Sidani et al., 2009), while other studies report that corruption has a low impact on trust in government in transition countries because people demand more basic services (Uslaner, 2014). Our results offer more support to the former.

Security was also identified as a means to repair trust. Respondents called for a national counterterrorism strategy and were willing to sacrifice freedom for greater security:

Government should ensure security and fight against terrorism. For me, security is more important and fundamental than freedom (Female, 2013, interview). 
Authors have previously identified security as a reason for citizens' cynicism (Chanley et al., 2000). Indeed, Chanley (2002) reported that trust in a government could increase when the government defends national security, particularly in developing countries (Espinal et al, 2006). Security is particularly important in Tunisia as the terrorist attacks have led to a significant decline in the tourism sector considered as the economic engine of the Tunisian economy. This response was categorized as trust transference in line with economic response (above).

Political parties. Many interviewed politicians and citizens (after all events) identified political experience as required to enable political parties to repair trust. Two contributors in TV political talk shows also mentioned this response. Experienced politicians are perceived to be more competent and trustworthy. It is interesting to note that the lack of political experience as an antecedent of political distrust could be specific to the Tunisian context as it is a new democracy. Indeed, most politicians in Tunisia had no experience with politics at the time of the study. A rule requiring that a proportion of politicians within any one party had to have political experience would be categorized as regulation and formal control within the trust repair framework.

Eight interviewed citizens and six politicians identified patriotism as a means to repair trust after the adoption of the constitution and 2014 elections. They called for politicians to be altruistic. Previous studies have examined the relationship between civic patriotism and political trust and involvement (Hetherington and Rudolph, 2008; Straughn and Andriot, 2011), however the impact of politicians' patriotism on political trust was not identified in previous studies. This has been classified as a cultural change that would constrain untrustworthy behaviour and hence placed under ethical culture and informal control in the Bachmann et al (2015) framework. The following schema (Table 1) summarizes our study main findings. 
Table 1 Classification of the trust repair responses according to the Bachmann et al (2015) mechanisms

\begin{tabular}{|c|c|c|c|}
\hline $\begin{array}{l}\text { Time } \\
\text { period }\end{array}$ & Response to: & $\begin{array}{l}\text { Mechanisms identified in the } \\
\text { study }\end{array}$ & $\begin{array}{l}\text { Bachmann et al (2015) } \\
\text { mechanism }\end{array}$ \\
\hline Swift & $\begin{array}{l}\text { Political } \\
\text { parties \& } \\
\text { political } \\
\text { institutions }\end{array}$ & Dialogue & Sensemaking \\
\hline \multirow[t]{8}{*}{ Short-term } & \multirow{4}{*}{$\begin{array}{l}\text { Political } \\
\text { parties }\end{array}$} & Realistic political program & Transparency and accountability \\
\hline & & $\begin{array}{l}\text { Abandoning quarrels and } \\
\text { agreements between political } \\
\text { parties }\end{array}$ & Ethical culture and informal control \\
\hline & & Apologies & Relational approach \\
\hline & & Explanations & Sensemaking \\
\hline & \multirow[t]{4}{*}{$\begin{array}{l}\text { Political } \\
\text { institutions }\end{array}$} & $\begin{array}{l}\text { Holding elections and adoption } \\
\text { of the constitution }\end{array}$ & Regulation and formal control \\
\hline & & $\begin{array}{l}\text { Technocratic Government/ } \\
\text { Resignation of Government/ } \\
\text { Dissolvement of National } \\
\text { Assembly }\end{array}$ & Regulation and formal control \\
\hline & & Revising ministers' salaries & Relational approach \\
\hline & & Involvement of a third party & Trust transference \\
\hline \multirow[t]{8}{*}{ Long-term } & \multirow{2}{*}{$\begin{array}{l}\text { Both political } \\
\text { parties and } \\
\text { government }\end{array}$} & Transparent communication & Transparency and accountability \\
\hline & & Keeping electoral promises & Ethical culture and informal control \\
\hline & \multirow[t]{4}{*}{ Government } & Economic responses & Trust transference \\
\hline & & Regulation & Regulation and formal control \\
\hline & & fight against corruption & Ethical culture and informal control \\
\hline & & ensuring security & Trust transference \\
\hline & \multirow{2}{*}{$\begin{array}{l}\text { Political } \\
\text { parties }\end{array}$} & Political experience & Ethical culture and informal control \\
\hline & & Patriotism & Ethical culture and informal control \\
\hline
\end{tabular}


An analysis across the different events (see Table 1) identifies not one, but a variety of trust repair responses. Also noticeable is an evolving pattern with the move from negative to more positive events. Following the 2013 assassinations, respondents were immediately seeking sense-making activities in order to understand what had happened. This was followed by a call for more regulation and control responses that would formally constrain untrustworthy behaviour and prevent future trust violations. Following the 2014 dialogue and constitution, respondents called for more symbolic and relational responses. Finally, in 2015 and post elections, respondents sought ethical responses and informal control. Although this change in trust repair responses might suggest a potential repair of trust, it is notable that regulation continues to be mentioned across the different events reinforcing a continued presence of distrust.

\section{DISCUSSION AND CONCLUSION}

The aim of this study was to identify the responses required to repair political trust in Tunisia and the differences between two key stakeholder groups: politicians and voters. This study is among a very few to identify an array of trust repair responses in the political domain. Past studies have tended to focus on single specific responses (for example, Kim and Kim, 2007; Moon, 2013). Our analysis identified that political actors and citizens were aware of the need to repair trust in government and political parties and identified a wide array of responses to repair lost trust.

The study makes five contributions to trust repair theory. First, this study has identified multiple trust repair responses beyond those identified in previous studies. For example, although the economic situation has been identified previously, it has been associated with a drop in political trust rather than a repair response (Hetherington, 1998). Previous studies have examined patriotism from a civic perspective (Straughn and Andriot, 2011) but the link between a politicians' patriotism and trust has not been previously established. Our study therefore suggested that political trust repair responses are 
potentially more numerous than previously stated and that multiple responses may be required to repair trust (Bachmann et al, 2015).

Second, we identified a new timescale within the trust repair calendar, i.e. swift trust repair. In this study, swift trust repair was required to deal with political uncertainty after a major trust violation: the assassination of the two political leaders. Lewicki and Brinsfield (2017) had previously identified short and long terms responses, however our respondents suggested that swift trust could provide a basic level of trust to enable an organization to move forward, in this case for the adoption of the constitution and holding of national elections.

Third, differences in responses were identified by stakeholder, namely politicians and voters. Previous studies have ignored the needs of different stakeholders (Bachman et al., 2015). This distinction is particularly important in this study as the differences were identified between the trustee and trustor which could result in a trust repair mis-match or gap that would hinder trust repair by the trustee.

Fourth, previous studies have focused mainly on the courses of action that the trustee undertakes to repair trust, under the assumption that the trustor is a passive observer. Contrary to these studies, our research has revealed that citizens can also be actively involved in the trust repair process, making it a dynamic and bilateral process. Indeed, our respondents suggest that civic engagement and accountability will lead to a more participative exercise of power. In this regard, citizens will be able to influence government priorities and ensure that their demands are met.

Finally, this study has demonstrated the applicability of Bachmann's trust repair framework. As this framework was developed in an organizational studies context, its applicability to other contexts had been questioned (Bozic, 2017) and only one study had established its use in a marketing context (see 
Bolat et al., 2020). The findings from this study establish the use of this integrative framework in a new context, political trust, and highlights how the use of the 6 mechanisms can help to identify patterns in the process of trust repair, i.e. how the different responses and mechanisms change over time as trust is slowly repaired.

\section{Managerial contributions}

Findings from our study provide Tunisian politicians with an insight into how to repair voter trust particularly following an extreme violation of trust. This study has identified a wide array of potential trust repair responses from which politicians can choose. For example, communication has been found to be important in terms of helping citizens to initially make sense of what has happened when things go wrong; and, also, in terms of transparency and building relationships with voters. Given the array of responses identified in this study it is important that political organizations consider using multiple responses to repair trust (Bachmann et al., 2015), not only over time but at any one specific point in time. Selection of the appropriate responses can be informed by the findings from this study. Caution is however recommended when politicians devise a trust repair response strategy as this study has highlighted clear differences between the responses suggested by politicians and those suggested by voters.

\section{Limitations and future research}

This study, as with any study, has its limitations. It focused on one MENA country, Tunisian. Other studies may address the differences between Tunisia and other Arab countries that have also experienced revolution (i.e. Egypt, etc.) and the responses required to repair trust in the political domain. Tunisian citizens were interviewed after the key events in 2013, 2014 and 2015, however the citizens varied in each round of interviews. Some differences in the responses identified could therefore be due to the change in interviewee rather than the events. We would recommend that future 
studies repeatedly interview the same interviewees as a form of interviewee panel. Finally, and following the recommendation of Bachmann et al. (2015) our research adopted a longitudinal study to identify suggested trust repair responses following selected key events. We did not examine in any depth whether these responses were adopted by political parties and the government or indeed, when they were adopted, were they successful in restoring trust. It is recommended that future studies adopt a longitudinal approach and measure the extent that trust has been repaired where the responses are adopted. 


\section{REFERENCES}

Ahmed, M. A., Lodhi, S. A., \& Shahzad, M. N. (2011), Political Brand: trusting a candidate in the age of mistrust. Journal of Business and Retail Management Research, 5(2), 131-141.

Bachmann, R., \& Inkpen, A. C. (2011). Understanding institutional-based trust building processes in inter-organizational relationships. Organization Studies, 32(2), 281-301.

Bachmann, R., Gillespie, N. \& Priem, R. (2015). Repairing Trust in Organizations and Institutions: Toward a Conceptual Framework. Organization Studies, 36 (9), 11231142.

Benoit, W. L., \& Henson, J. R. (2009), President Bush's image repair discourse on Hurricane Katrina. Public Relations Review, 35(1), 40-46.

Bolat, E., Robson, J., Sit, K. J., Birch-Chapman, S., Ashraf, S., Memery, J., \& Jackson, C. (2020). Service brand rehab: diagnosing trust repair mechanisms. Qualitative Market Research: An International Journal. DOI: https://doi.org/10.1108/QMR-12-2017-0187

Boursin, F. (1999), Crise de la confiance ou de la communication politique ? Communication et organization, (16).

Bozic, B. (2017). Consumer trust repair: A critical literature review. European Management Journal, $35(4), 538-547$.

Brillantes Jr, A. B., \& Fernandez, M. T. (2011), Restoring trust and building integrity in government: issues and concerns in the Philippines and areas for reform. International Public Management Review, 12(2), 55-80.

Chanley, V. A., Rudolph, T. J., \& Rahn, W. M. (2000), The origins and consequences of public trust in government: A time series analysis. Public opinion quarterly, 64(3), 239-256.

Chanley, V. A. (2002), Trust in Government in the Aftermath of 9/11: Determinants and Consequences. Political psychology, 23(3), 469-483.

Dietz, G., \& Gillespie, N. (2012). Recovery of trust: Case studies of organisational failures and trust repair (Vol. 5). London: Institute of Business Ethics.

Dirks, K. T., Lewicki, R. J., \& Zaheer, A. (2009). Reparing relationships within and between organizations: building a conceptual foundation. Academy of Management Review, 34(1), 68-84.

Dirks, K. T., Kim, P. H., Ferrin, D. L., \& Cooper, C. D. (2011), Understanding the effects of substantive responses on trust following a transgression. Organizational Behavior and Human Decision Processes, 114(2), 87-103.

Eberl, P., Geiger, D., \& Aßländer, M. S. (2015), Repairing trust in an organization after integrity violations: The ambivalence of organizational rule adjustments. Organization Studies, 36(9), 12051235 .

Edelman (2020) 2020 Edelman Trust Barometer. 19th January 2020. Available at: https://www.edelman.com/trustbarometer. Accessed 31st January 2020. 
Espinal, R., Hartlyn, J., \& Kelly, J. M. (2006), Performance still matters: Explaining trust in government in the Dominican Republic. Comparative Political Studies, 39(2), 200-223.

Esser, F., \& Hartung, U. (2004), Nazis, pollution, and no sex: Political scandals as a reflection of political culture in Germany. American Behavioral Scientist, 47(8), 1040-1071.

Farrell, J., \& Rabin, M. (1996), “Cheap talk”. The Journal of Economic Perspectives, 10(3), 103-118.

Franzosi, R. (1998), Narrative analysis - or why (and how) sociologists should be interested in narrative. Annual review of sociology, 24(1), 517-554.

Garcia, C. (2011). Sex scandals: A cross-cultural analysis of image repair strategies in the cases of Bill Clinton and Silvio Berlusconi. Public Relations Review, 37(3), 292-296.

Gillespie, N., \& Dietz, G. (2009), Trust repair after an organization-level failure. Academy of Management Review, 34(1), 127-145.

Glaser, B., \& Strauss, A. (1967), Grounded theory: The discovery of grounded theory. Strategies for Qualitative Research. Chicago: Aldine.

Grabher, G. (2002), Cool projects, boring institutions: temporary collaboration in social context. Regional studies, 36(3), 205-214.

Grimmelikhuijsen, S., Porumbescu, G., Hong, B., \& Im, T. (2013), The effect of transparency on trust in government: A cross-national comparative experiment. Public Administration Review, 73(4), 575586.

Grover, S. L., Hasel, M. C., Manville, C., \& Serrano-Archimi, C. (2014), Follower reactions to leader trust violations: A grounded theory of violation types, likelihood of recovery, and recovery process. European Management Journal, 32(5), 689-702.

Harris, P., \& Lock, A. (2010), Mind the gap: the rise of political marketing and a perspective on its future agenda. European Journal of Marketing, 44(3-4), 297-307.

Hetherington, M. J. (1998), The political relevance of political trust. American political science review, 92(4), 791-808.

Hetherington, M. J. (1999), The effect of political trust on the presidential vote, 1968-96. American Political Science Review, 93(2), 311-326.

Hetherington, M. J., \& Rudolph, T. J. (2008), Priming, performance, and the dynamics of political trust. The Journal of Politics, 70(2), 498-512.

Kim, P. H., Ferrin, D. L., Cooper, C. D., \& Dirks, K. T. (2004), Removing the shadow of suspicion: the effects of apology versus denial for repairing competence-versus integrity-based trust violations. Journal of applied psychology, 89(1), 104-118.

Kim, B. S., \& Kim, J. H. (2007), Increasing trust in government through more participatory and transparent government. Presidential Committee on Government Innovation \& Decentralization, Republic of Korea. 
Klabi, F. (2012), Comment expliquer les résultats des élections Tunisiennes de l'Assemblée Constituante par l'approche de la personnalité des marques ? . 10ème Colloque International de l'ATM

Klein Woolthuis, R. J. A., Nooteboom, B., De Jong, G., Wick, A., Harris, J., \& Moriarty, B. (2014), Roles of Third Parties in Trust Repair-An Empirical Test in High Tech Industries, in A. Wick, J. Harris, \& B. Moriarty (Eds.), Public Trust in Business Cambridge: Cambridge University Press, 290-325.

Lambsdorff, J. G. (2007), The institutional economics of corruption and reform: theory, evidence and policy. Cambridge University Press.

Lewicki, R. J., \& Wiethoff, C. (2000), Trust, trust development, and trust repair. The handbook of conflict resolution: Theory and practice, 1(1), 86-107.

Lewicki, R. J., \& Brinsfield, C. (2017), Trust Repair. Annual Review of Organizational Psychology and Organizational Behavior, 4 (2), 287-313.

Liao, T. F. (2010), Visual symbolism, collective memory, and social protest: A study of the 2009 London G20 protest. Social Alternatives, 29(4), 37-43.

Lincoln, Y. S., \& Guba, E. G. (1985), Naturalistic inquiry (Vol. 75). Sage.

Maddux, W. W., Kim, P. H., Okumura, T., \& Brett, J. M. (2011), Cultural differences in the function and meaning of apologies. International Negotiation, 16(3), 405-425.

Martin, G. (2011). Human values and ethics in the workplace. Lulu. com.

Mayer, R. C., Davis, J. H., \& Schoorman, F. D. (1995). An integrative model of organizational trust. Academy of Management Review, 20(3), 709-734.

McKendall, M. A., \& Wagner III, J. A. (1997). Motive, opportunity, choice, and corporate illegality. Organization Science, 8(6), 624-647.

Merrington, S., Gillespie, N., Ferrin, D., \& Dietz, G. (2011), How do leaders repair trust? An examination of trust repair during the UK expenses scandal. In 25th Annual Australian and New Zealand Academy of Management (ANZAM) Conference (pp. 1-20) Australian and New Zealand Academy of Management.

Meyerson, D., Weick, K. E., \& Kramer, R. M. (1996), Swift trust and temporary groups. In R. M. Kramer \& T. R. Tyler (Eds.), Trust in organizations: Frontiers of theory and research, 166-195. Thousand Oaks, CA, US: Sage Publications, Inc.

Möllering, G. (2013). Process views of trusting and crises. In R. Bachmann and A. Zaheer (eds), Handbook of Advances in Trust Research, Cheltenham: Edward Elgar, pp. 285-305.

Moon, J. A. (2013), Reflection in learning and professional development: Theory and practice. Routledge.

O’Neill, Onora. (2002), A question of trust: The BBC Reith lectures 2002. Cambridge University Press. 
Ouannès, M. (2010). La personnalité tunisienne. Editions Mediterraneen Publishers.

Patton, M. Q. (2002). Two decades of developments in qualitative inquiry: A personal, experiential perspective. Qualitative social work, 1(3), 261-283.

Peng, X., Gong, W., \& Peng, M. (2016), Empirical Study on Trust Repair of Government in Public Crisis Event. Open Journal of Business and Management, 4(02), 376-391.

Pétry, F. (2014), A Tale of Two Perspectives: Election Promises and Government Actions in Canada. In E. Gidengil \& H. Bastedo (Eds.), Canadian Democracy From the Bottom Up (pp. 231-252).

Pfarrer, M. D., Decelles, K. A., Smith, K. G., \& Taylor, M. S. (2008). After the fall: Reintegrating the corrupt organization. Academy of Management Review, 33(3), 730-749.

Ren, H., \& Gray, B. (2009), Repairing relationship conflict: How violation types and culture influence the effectiveness of restoration rituals. Academy of Management Review, 34(1), 105-126.

Rouissi, M. (1987), Espace et société: l'équation tunisienne, in Tunisie au présent, C.N.R.S., 53-64.

Rousseau, D. M., Sitkin, S. B., Burt, R. S., \& Camerer, C. (1998). Not so different after all: A crossdiscipline view of trust. Academy of management review, 23(3), 393-404.

Shapiro, D. L. (1991), The effects of explanations on negative reactions to deceit. Administrative science quarterly, 36(4), 614-630.

Shapiro, D. L., Buttner, E. H., \& Barry, B. (1994), Explanations: What factors enhance their perceived adequacy? Organizational behavior and human decision processes, 58(3), 346-368.

Sidani, Y., Zbib, I., Rawwas, M., \& Moussawer, T. (2009), Gender, age, and ethical sensitivity: the case of Lebanese workers. Gender in Management: An International Journal, 24(3), 211-227.

Skandrani, H., Triki, A., \& Baratli, B. (2011), Trust in supply chains, meanings, determinants and demonstrations: A qualitative study in an emerging market context. Qualitative Market Research: An International Journal, 14(4), 391-409.

Straughn, J. B., \& Andriot, A. L. (2011), Education, Civic Patriotism, and Democratic Citizenship: Unpacking the Education Effect on Political Involvement. In Sociological Forum (Vol. 26, No. 3, pp. 556-580). Oxford, UK: Blackwell Publishing Ltd.

Teti A., Abbott P., \& Cavatorta F. (2018), Introduction and Background. In: The Arab Uprisings in Egypt, Jordan and Tunisia. Reform and Transition in the Mediterranean. Palgrave Macmillan, Cham.

Tolbert, C. J., \& Mossberger, K. (2006), The effects of e-government on trust and confidence in government. Public administration review, 66(3), 354-369.

Tomlinson, E. C., \& Mryer, R. C. (2009). The role of causal attribution dimensions in trust repair. Academy of Management Review, 34(1), 85-104.

Torcal, M. (2014), The decline of political trust in Spain and Portugal: economic performance or political responsiveness? American Behavioral Scientist, 58(12), 1542-1567. 
Tweedale, G (2003), Researching corporate crime. A business historian's perspective. In S. Tombs, \& D. Whyte (Eds), Unmasking the crimes of the powerful. Scrutinizing states \& corporations (pp. 6987). Springer, Netherlands : Peter Lang.

Uslaner, E. M. (2014), Corruption, inequality, and trust in government. Handbook on Political Trust. United Kingdom: Cheltenham.

Weick, K. (1995). Sensemaking in organizations. Thousand Oaks, CA: Sage

West, D. M. (2004), E-government and the transformation of service delivery and citizen attitudes. Public administration review, 64(1), 15-27.

Yin, R. (2018), Case Study Research and Applications Design and Methods (Sixth Edition), Thousand Oaks, Sage Publications.

Yu, Y., Yang, Y., \& Jing, F. (2017). The role of the third party in trust repair process. Journal of Business Research, 78, 233-241.

Zucker, L. G. 1986. The production of trust: Institutional sources of economic structure, 1840-1920. In B. M. Staw \& L. L. Cummings (Eds.), Research in organizational behavior, 8: 53-1 11. Greenwich, CT: JAI Press. 
Appendix A. Sample description: citizens

\begin{tabular}{|l|l|l|l|l|l|}
\hline \multicolumn{7}{|c|}{2013} \\
\hline & Gender & Age & Education Level & Profession & Region \\
\hline $\mathbf{1}$ & Female & $55-64$ & Secondary level & Housewife & $\begin{array}{l}\text { Tunis/ } \\
\text { France }\end{array}$ \\
\hline $\mathbf{2}$ & Male & $65-74$ & Secondary level & Retired & Beja \\
\hline $\mathbf{3}$ & Female & $18-24$ & University level & Student & Sousse \\
\hline $\mathbf{4}$ & Female & $18-24$ & Secondary level & Student & Sousse \\
\hline $\mathbf{5}$ & Male & $25-34$ & University level & Engineer & $\begin{array}{l}\text { Kairouan } \\
\text { France }\end{array}$ \\
\hline $\mathbf{6}$ & Female & $25-34$ & Secondary level & Secretary & Ben Arous \\
\hline $\mathbf{7}$ & Female & $35-44$ & University level & Senior officer & Tunis \\
\hline $\mathbf{8}$ & Male & $45-54$ & Primary level & Worker & Tozeur \\
\hline $\mathbf{9}$ & Female & $25-34$ & University level & Senior officer & Nabeul \\
\hline $\mathbf{1 0}$ & Male & $45-54$ & University level & Senior officer & Kef \\
\hline 11 & Male & $45-54$ & Secondary level & Unemployed & Zaghouan \\
\hline
\end{tabular}

\begin{tabular}{|l|l|l|l|l|l|}
\hline \multicolumn{7}{|c|}{2014} \\
\hline & Gender & Age & Education Level & Profession & Region \\
\hline $\mathbf{1}$ & Male & $25-34$ & University level & Journalist & Ben Arous \\
\hline $\mathbf{2}$ & Male & $35-44$ & University level & Businessman & Ariana \\
\hline $\mathbf{3}$ & Male & $35-44$ & Secondary level & Activist & Kasserine \\
\hline 4 & Male & $65-74$ & Secondary level & Retired & Ben Arous \\
\hline $\mathbf{5}$ & Female & $35-44$ & Primary level & Housekeeper & Tunis \\
\hline 6 & Female & $45-54$ & Primary level & Unemployed & Tunis \\
\hline $\mathbf{7}$ & Male & $45-54$ & Primary level & Courier & Jendouba \\
\hline $\mathbf{8}$ & Male & $55-64$ & Primary level & Gatekeeper & Tunis \\
\hline 9 & Male & $45-54$ & Secondary level & Banker & Tunis \\
\hline 10 & Female & $45-54$ & Secondary level & Banker & Ben Arous \\
\hline $\mathbf{1 1}$ & Male & $55-64$ & University level & Senior officer & Ariana \\
\hline $\mathbf{1 2}$ & Male & $45-54$ & University level & Architect & Ariana \\
\hline $\mathbf{1 3}$ & Male & $45-54$ & Secondary level & Worker & Sousse \\
\hline $\mathbf{1 4}$ & Female & $25-34$ & Secondary level & Unemployed & Nabeul \\
\hline $\mathbf{1 5}$ & Male & $18-24$ & University level & Student & Medenine \\
\hline 16 & Male & $18-24$ & University level & Student & Beja \\
\hline $\mathbf{1 7}$ & Male & $25-34$ & Secondary level & Employee & Siliana \\
\hline $\mathbf{1 8}$ & Male & $55-64$ & University level & Judge & Tunis \\
\hline
\end{tabular}

\begin{tabular}{|l|l|l|l|l|l|}
\hline \multicolumn{7}{|c|}{2015} \\
\hline & Gender & Age & Education Level & Profession & Region \\
\hline 1 & Female & $25-34$ & University level & Unemployed & Kasserine \\
\hline 2 & Male & $25-34$ & University level & Technician & Siliana \\
\hline 3 & Male & $18-24$ & University level & Student & Bizerte \\
\hline 4 & Female & $35-44$ & University level & Housekeeper & Ben Arous \\
\hline 5 & Female & $25-34$ & University level & Unemployed & Beja \\
\hline 6 & Female & $25-34$ & University level & Banker & Mahdia \\
\hline 7 & Male & $25-34$ & University level & Professor & Monastir \\
\hline 8 & Female & $35-44$ & Primary level & Housekeeper & Kef \\
\hline 9 & Female & $55-64$ & University level & Teacher & Kairouan \\
\hline 10 & Male & $18-24$ & Primary level & Unemployed & Tataouine \\
\hline 11 & Female & $25-34$ & University level & Banker & Tozeur \\
\hline 12 & Male & $25-34$ & University level & Banker & Jendouba \\
\hline 13 & Male & $45-54$ & University level & Teacher & Gafsa \\
\hline 14 & Female & $35-44$ & University level & Senior officer & Kebili \\
\hline 15 & Male & $35-44$ & Secondary level & Employee & Gabes \\
\hline 16 & Female & $18-24$ & University level & Student & Sidi \\
& & & & & Bouzid \\
\hline 17 & Female & $18-24$ & Secondary level & Student & Sfax \\
\hline 18 & Male & $25-34$ & University level & Technician & Medenine \\
\hline 19 & Female & $25-34$ & University level & PhD student & Manouba \\
\hline 20 & Female & $25-34$ & University level & Senior officer & Nabeul \\
\hline
\end{tabular}




\begin{tabular}{|c|c|c|c|c|c|c|c|}
\hline \multicolumn{4}{|c|}{2013} & \multicolumn{4}{|c|}{2014} \\
\hline & Gender & Age & Opposition /Ruling party & & Gender & Age & Opposition /Ruling party \\
\hline 1 & Male & $35-44$ & Ruling party (Troika) & 1 & Male & $35-44$ & Opposition \\
\hline 2 & Male & $35-44$ & Opposition & 2 & Male & $75-84$ & Ex-ruling party \\
\hline 3 & Male & $75-84$ & Ex-ruling party & 3 & Male & $45-54$ & Ex-ruling party \\
\hline 4 & Female & $45-54$ & Ruling party (Troika) & 4 & Male & $65-74$ & Ex-ruling party/opposition \\
\hline 5 & Male & $45-54$ & Ex-ruling party & 5 & Male & $35-44$ & Ex-ruling party \\
\hline 6 & Female & $45-54$ & Opposition & 6 & Male & $45-54$ & Opposition \\
\hline 7 & Male & $45-54$ & Ruling party (Troika) & 7 & Male & $65-74$ & Ruling party (Troika) \\
\hline 9 & Male & $35-44$ & Ex-Ruling party & 9 & Male & $45-54$ & Opposition \\
\hline 10 & Female & $45-54$ & Opposition & 10 & Male & $45-54$ & Ex-Ruling party \\
\hline 11 & Male & $45-54$ & Opposition & 11 & Male & $35-44$ & Opposition \\
\hline 12 & Male & $45-54$ & Opposition & 12 & Male & $45-54$ & Opposition \\
\hline 13 & Male & $65-74$ & Ruling party (Troika) & 13 & Male & $65-74$ & Ruling party (Troika) \\
\hline 14 & Male & $35-44$ & Ex-Ruling party & 14 & Male & $25-34$ & Opposition \\
\hline 15 & Male & $45-54$ & Opposition & 15 & Male & $55-64$ & Opposition \\
\hline 16 & Female & $55-64$ & Opposition & 16 & Male & $85-94$ & Opposition \\
\hline 19 & Male & $45-54$ & Opposition & 19 & Male & $45-54$ & Ruling party (Troika) \\
\hline 20 & Male & $45-54$ & Opposition & 20 & Male & $45-54$ & Opposition \\
\hline 21 & Male & $65-74$ & Ruling party (Troika) & 21 & Male & $75-84$ & Ex-ruling party/ Opposition \\
\hline 22 & Male & $25-34$ & Opposition & \multicolumn{4}{|c|}{2015} \\
\hline 23 & Male & $55-64$ & Opposition & & Gender & Age & Opposition /Ruling party \\
\hline 24 & Female & $55-64$ & Opposition & 1 & Female & $25-34$ & Ruling party \\
\hline 25 & Male & $35-44$ & Ruling party (Troika) & 2 & Female & $45-54$ & Ruling party \\
\hline 26 & Male & $45-54$ & Ex-nling parts & 3 & Male & $25-34$ & Ruling party \\
\hline$+\infty$ & Dere & & Ex-ruing party & 4 & Male & $55-64$ & Ruling party \\
\hline 27 & Male & $25-34$ & Opposition & 5 & Female & $35-44$ & Opposition \\
\hline 28 & Male & $45-54$ & Opposition & 6 & Male & $65-74$ & Opposition \\
\hline 29 & Male & $45-54$ & Ruling party (Troika) & 7 & Male & $45-54$ & Opposition \\
\hline & & & & 8 & Male & $45-54$ & Ruling party \\
\hline 30 & Male & $45-54$ & Opposition & 9 & Male & $45-54$ & Ruling party \\
\hline 31 & Male & $75-84$ & Ex-ruling party/Opposition & 10 & Male & $45-54$ & Opposition \\
\hline
\end{tabular}

Appendix B: Sample description: politicians 